\title{
IT Supporting Strategy Formulation
}

\author{
Jan Achterbergh \\ Radboud University of Nijmegen, The Netherlands
}

\section{INTRODUCTION}

This overview approaches information and communication technology (ICT) for competitive intelligence from the perspective of strategy formulation. It provides an ICT architecture for supporting the knowledge processes producing relevant knowledge for strategy formulation.

To determine what this architecture looks like, we first examine the process of strategy formulation and determine the knowledge required in the process of strategy formulation. To this purpose, we use Beer's viable system model (VSM). Second, we model the knowledge processes in which the intelligence relevant for the process of strategy formulation is produced and processed. Given these two elements, we describe an ICT architecture supporting the knowledge processes producing the knowledge needed for the strategic process.

\section{BACKGROUND: STRATEGY FORMULATION, A VIABLE SYSTEM PERSPECTIVE}

Strategy formulation aims at developing and selecting goals and plans securing the adaptation of the organization to its environment. These goals and plans may refer to specific product-market-technology combinations (PMCs) for which the organization hypothesizes that they ensure a stable relation with its environment. The process of strategy formulation needs to generate such goals and plans, needs to reflect upon their appropriateness, and needs to select certain goals and plans to guide the behavior of the organization. This is a continuous process. Goals and plans can be seen as hypotheses about what will work as a means to adapt and survive. Therefore, they should be monitored constantly and revised if necessary. In short, strategy formulation is a continuous contribution to maintaining organizational viability.

Although many authors deal with the process of strategy formulation, we choose the viable system model of Beer $(1979,1981,1985)$ to define this process more closely. We select the VSM because Beer explicitly unfolds the functions required for the viable realization and adaptation of an organization's strategy.

To explain what these functions entail, it is useful to divide them into two groups: functions contributing to the realization of the organization's strategy and functions contributing to its adaptation.

The first group deals with the realization of the organization's strategy. It consists of three functions. Function 1 comprises the organization's primary activities constituting its "raison d'être" (Espejo, Schumann, Schwaninger, \& Billello, 1996, p. 110). Function 2 (coordination) coordinates interdependencies between these primary activities. The third function is called the control function. It ensures the synergy of and cohesion between the primary activities by specifying their goals and controlling their performance.

To illustrate these functions, consider Energeco, a company servicing its environment with eco-energy. Function 1 of Energeco consists of three primary activities: supplying solar, tidal, and wind energy. To give an example of the coordination function, suppose that specialists in high-voltage energy are a shared resource between Energeco's business units. Also suppose that there is no coordination between these business units. In this case, the allocation of high-voltage specialists to a project in the business unit Solar Energy may require a revision of the allocation of these same specialists to a project in the business unit Wind Energy. Without a function supporting the coordination of these interdependencies, the business units Solar Energy and Wind Energy may become entangled in a process that oscillates between allocating and revising the allocation of these specialists to projects. It is the task of Function 2 to coordinate these interdependencies. The control function's task is to translate the identity and mission of the viable system (for Energeco, supplying eco-energy) into goals for the primary activities (in this example, supplying wind, solar, and tidal energy) and to control the realization of these goals.

The second group deals with the adaptation of the organization's strategy. It consists of control (Function 3 ), intelligence (Function 4), and policy (Function 5). Intelligence scans the organization's relevant environment and generates and proposes plans for adaptation. In the example of Energeco, developments in production technology may introduce the possibility of cost-effective, large-scale production of eco-energy from biomass. Intelligence should pick up these developments, assess them, and if relevant, translate them into proposals for 
innovation. Because of its knowledge of the potentials for change of the primary activities, control (Function 3) reviews the feasibility of the plans proposed by intelligence. For instance, it may object to the plans proposed by intelligence because they require a change posing a risk to the performance of the primary activities.

Discussion about the relevance and feasibility of the proposals for adaptation between intelligence and control should produce finalized plans for adaptation. It is the task of the policy function to balance the discussion between intelligence and control and to consolidate the finalized proposal in the organization's strategy. For instance, in the discussion between intelligence and control about the feasibility of the adoption of large-scale production of eco-energy from biomass, the policy function should ensure that control and intelligence are equally represented in the discussion. By opting for the production of energy from biomass, the policy function consolidates producing eco-energy from biomass as a new goal for Energeco. Figure 1 depicts the process of strategy formulation in terms of the VSM functions and activities.

To contribute to the strategy-formulation process, control, intelligence, and policy require knowledge about particular domains. Table 1 provides an overview of the knowledge required by each function to contribute to the process of strategy formulation.

Given the overview of functions involved in the strategy-formulation process, their relations, and the knowledge required by these functions to contribute to the process of strategy formulation, it is now possible to look into the knowledge processes needed to produce this knowledge and the ICT architecture supporting these knowledge processes.

\section{KNOWLEDGE PROCESSES CONTRIBUTING TO STRATEGY FORMULATION}

The question for this section is by means of what processes knowledge in the knowledge domains should be produced and processed so that the process of strategy formulation can take place. To answer this question, we first need to specify what these knowledge processes are. Then we need to link these processes to the knowledge required by control, intelligence, and policy to contribute to the strategy-formulation process.

We distinguish four relevant processes for producing and processing knowledge: generating $(\mathrm{G})$, sharing (S), retaining (R), and applying (A) knowledge (cf. Achterbergh \& Vriens, 2002; Bukowitz \& Williams, 1999; Davenport \& Prusak, 1998).

These four knowledge processes can now be linked to the process of strategy formulation, as formulated according to the VSM. According to the VSM, the functions intelligence, control, and policy contribute to strategy formulation. This contribution involves the application of knowledge in the knowledge domains to arrive at the four core products of strategy formulation: proposals for innovation, their reviews, the finalized plans for innovation, and their consolidation. The knowledge applied by each function is generated either by that function or by one of the other functions of the VSM. In the latter case, knowledge must be shared between functions. Applying, generating, and sharing knowledge requires the retention or storage of knowledge.

Figure 1. The process of strategy formulation according to the VSM

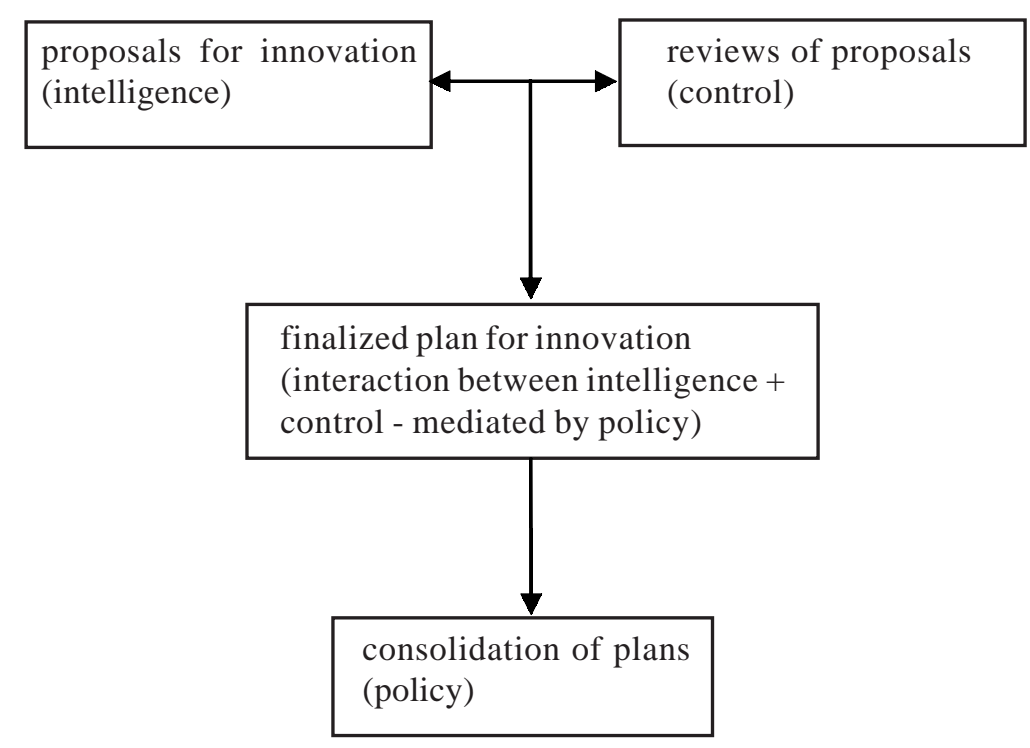


Table 1. Knowledge required by each function to contribute to the strategy formulation process

\begin{tabular}{|l|l|}
\hline Function & Related domains of knowledge \\
\hline (control) & For reviewing F4 proposals \\
& Organizational goals \\
& Proposals for innovation made by F4 \\
& Desired goals for F1 based on proposals for innovation \\
& Expected performance of the primary activities (goals for F1 activities) \\
& Gap between desired and current goals for F1 \\
& Required capacity for reorganization of F1 activities \\
& Modus operandi of F1 activities \\
& Actual capacity for reorganization of F1 activities \\
& Gap between required and actual capacity for reorganization \\
& Review of proposals for innovation \\
& Finalized plans for adaptation of organizational goals (a joint F3 and F4 product) \\
& Regulatory measures to counter the imbalance between F3 and F4 (see Function 5) \\
\hline F4: Function 4 & Organizational goals \\
Goals set by performance and modus operandi of F1 activities & Developments in the relevant environment of the organization \\
& Reviews by F3 of proposals for innovation \\
& Regulatory measures to counter the imbalance between F3 and F4 (see Function 5) \\
& Finalized plans for adaptation of organizational goals (a joint F3 and F4 product) \\
\hline F5: Function 5 (policy) & For balancing purposes \\
& Norms for balance between F3 and F4 \\
& Proposals by F4 and their reviews by F3 (relative contribution of F3 and F4 to the \\
& discussion on adaptation) \\
& Actual (im)balance between F3 and F4 \\
& Causes of imbalance between F3 and F4 \\
& Experiences with regulatory measures to counter the imbalance between F3 and F4 \\
& Regulatory measures to counter the imbalance between F3 and F4 \\
& For consolidation purposes \\
& Finalized plans for adaptation of organizational goals (a joint F3 and F4 product) \\
& Organizational goals \\
\hline
\end{tabular}

Table 2 provides an overview of the relation between the five functions in the VSM, the knowledge domains, and the application and generation of knowledge in these domains. Based on this table, it is possible to draw conclusions about sharing and retaining knowledge. In the table we only included the relevant knowledge for strategy formulation. However, some of this knowledge is generated by Function 1; this is the reason of its inclusion in the table.

The first column of Table 2 summarizes the knowledge domains listed in Table 1. In this column, we eliminated all redundant entries. Columns 2 to 5 indicate whether knowledge in a specific knowledge domain is generated and/or applied by a specific function.

Given the link between the knowledge processes, the functions contributing to the strategy-formulation process, and the knowledge required by them, it is now possible to outline an ICT architecture that can support the generating, retaining, sharing, and applying of this knowledge by these functions.

\section{AN ICT ARCHITECTURE SUPPORTING KNOWLEDGE PROCESSES NEEDED FOR STRATEGY FORMULATION}

Knowledge from several knowledge domains specified in Table 2 should be generated, stored, shared, and applied to take the steps in the process of strategy formulation: formulating proposals for innovation, reviewing them, making finalized plans for innovation, and consolidating them. We use these steps in the process of strategy formulation as a point of departure for outlining an ICT architecture (cf. Laudon \& Laudon, 1997; Tan, 2003; Turban, McLean, \& Wetherbe, 2002) for an information system supporting this process. In the literature, ICT architectures are presented as conceptual models, specifying (at a general level) the parts of an ICT infrastructure (applications, databases, technological ICT elements) and their relations. In this chapter we focus on 
Table 2. Functions, knowledge domains, and knowledge processes for strategy formulation

\begin{tabular}{|l|l|l|l|l|}
\hline Knowledge domains & F1 & F3 & F4 & F5 \\
\hline Goals set by performance and modus operandi of the primary activities in F1 & G,A & A & A & \\
Organizational goals & A & A & A & G,A \\
Proposals for innovation made by F4 & & A & G,A & A \\
Desired goals for F1 based on proposals for innovation & & G,A & & \\
Gap between desired and current goals of F1 & & G,A & & \\
Required capacity for reorganization of F1 activities & & G,A & & \\
Actual capacity for reorganization of F1 activities & & G,A & & \\
Gap between required and actual capacity for reorganization of F1 activities & & G,A & & \\
Reviews by F3 of proposals for innovation & & G,A & A & A \\
Finalized plans for adaptation of organizational goals (a joint F3 and F4 product) & & G,A & G,A & A \\
Regulatory measures to counter the imbalance between F3 and F4 & & A & A & G,A \\
Developments in the relevant environment of the organization & & G,A & \\
Norms for balance between F3 and F4 & & & G,A \\
Actual imbalance between F3 and F4 & & G,A \\
Causes of imbalance between F3 and F4 & & G,A \\
Experiences with regulatory measures to counter the imbalance between F3 and F4 & & & G,A \\
\hline
\end{tabular}

Figure 2. Outline of an architecture of an information system supporting strategy formulation

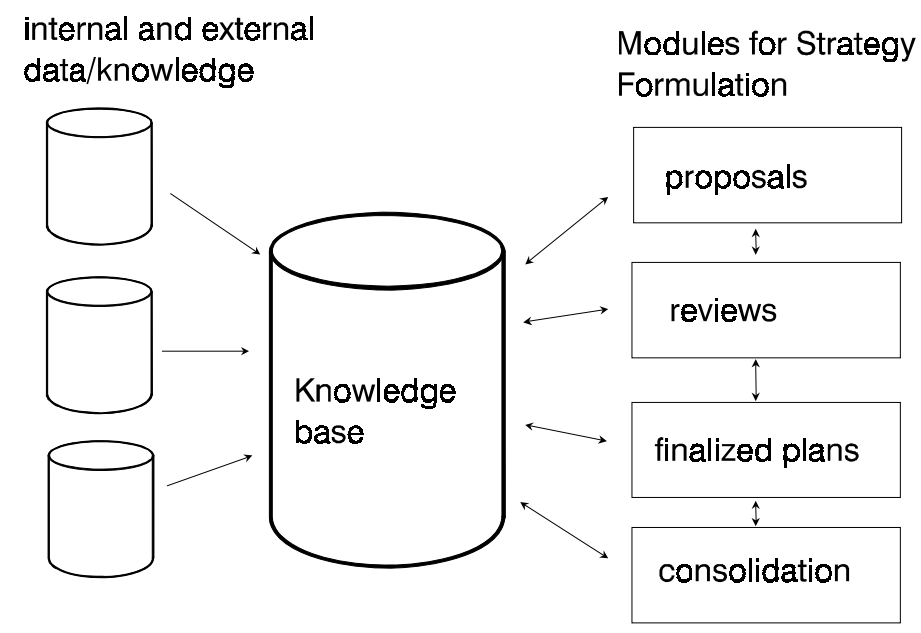

the application and databases parts. An outline of the architecture is presented in Figure 2.

This architecture consists, ideally, of five modules and knowledge and/or databases. The modules (at the right in Figure 2) are applications helping to generate the products of the process of strategy formulation. With the help of these modules, the knowledge from the knowledge domains is applied to produce the proposals, reviews, and (consolidated) plans. The architecture further consists of a central knowledge base in which the knowledge in the knowledge domains necessary for strategy formulation (see Table 2) is stored. This central knowledge base in turn may receive knowledge from other internal and external knowledge and/or databases. Below, we discuss the modules and knowledge bases and their relation to rel- evant knowledge processes in the course of strategy formulation in more detail.

1. The proposal module

The main product of this module is a list of innovation proposals and their justification. To produce this list, one should have access to the knowledge in the relevant knowledge domains. To generate this knowledge, the module should have access to external and internal information. For instance, it may have access to a data warehouse by means of a front-end tool, or it may have access to external online databases. Furthermore, the module may have access to a database consisting of previously re- 
jected or accepted proposals. The proposals for innovation produced with this module are stored in the central knowledge base.

2. The review module

The input for this module consists of the proposals for innovation. The output is a list of accepted and rejected proposals and the reasons for their acceptance or rejection. To make this list, the module should apply the knowledge in the central knowledge base. This knowledge may be available or may have to be generated. To generate the knowledge, access to several internal and external databases may be required. Also, (external) data on the results of the current PMCs may be input for rejecting or accepting innovations. The review module may benefit from a database with (a classification of) reasons for acceptance or rejection.

\section{The finalized-plans module}

This module is mainly a means for sharing proposals for innovation (and their reviews) in order to arrive at a finalized plan. It overarches the proposal and review module. By means of this module, results of the review module are shared and applied to revise the proposals (with the aid of the proposal module). The revised proposals are, in turn, used to produce new reviews (with the aid of the review module) and so forth. This module should (a) facilitate sharing proposals and (b) ensure the finalization of an innovation plan. To these ends, this module should support sharing knowledge about

- the rules for interaction (such as discussion format and deadlines),

- criteria for imbalance in the discussion,

- a monitoring function regarding the imbalance,

- rules and incentives for countering this imbalance, and

- an overview of the history of the discussion (as well as an overview of previous discussion).

Implementation could be by means of intranet applications (e.g., an internal discussion site).

4. The consolidation module

This module has as its output the consolidation of (a specific selection of) the innovations on the finalized list of innovations. To make this selection, the arguments used in the previous modules should be scanned and valued. Its main goal is to share the results of the strategy-formulation process with relevant parties in the organization. It should enable sharing knowledge about (a) the selected innovations, (b) the reasons for their selection, and (c) their consequences for the current way of doing business. The process of sharing may benefit from a database with (previously successful) communication formats that can be a part of the consolidation module.

5. The central knowledge base

The central knowledge base consists of all the knowledge in the knowledge domains relevant for strategy formulation. The knowledge base stores the knowledge produced in the modules and supports these modules by servicing them with knowledge relevant to their processes.

Above, an ICT architecture is outlined for an information system supporting strategy formulation. It shows how support should be focused on the products of strategy formulation. Moreover, the focus of the support is on the four knowledge processes involved in the production of proposals, reviews, plans, and consolidations. That is, the application of knowledge leads to proposals for innovation, reviews of these proposals, finalized plans, and consolidation of selected finalized plans. For these products, knowledge from the knowledge domains should be generated, stored, and/or shared. This knowledge is (partly) stored in the knowledge base. The knowledge may be generated by using the four modules and/or by using internal or external databases. Furthermore, knowledge from the knowledge domains may be shared by using connections between the modules.

The description of the architecture specifies the functionality of the different modules in it and how they should be connected. These specifications can be used to select or build the ICT tools to realize the architecture and the knowledge processes it supports.

\section{FUTURE TRENDS}

Given the particular outline of the proposed ICT architecture supporting the strategy formulation process, it is possible to link up with current trends that may enhance its performance.

- Developments in the technology for integrating databases (e.g., data warehouse technology) may support the intelligence function in the proposal phase by facilitating the integration and analysis of internal and external knowledge required for strategy formulation.

- Currently, data warehouses are often organized to fit the format of the Balanced Business Scorecard (Kaplan \& Norton, 2001). This scorecard is primarily 
geared to strategy implementation. The format of the VSM, its related knowledge domains, and steps for formulating strategy may be used to organize data warehouses to fit the requirements for strategy adaptation (Achterbergh, Beeres, \& Vriens, 2003).

- $\quad$ Proposing and reviewing proposals for adaptation may be enhanced by the application of computeraided techniques such as gaming, system dynamics, scenario analysis, and group model building.

- $\quad$ By systematically linking strategy formulation to knowledge management, it becomes possible to enhance the quality of the knowledge processes related to strategy formulation by using acquired insights on improving infrastructures for knowledge management.

\section{CONCLUSION}

In this overview, we design an ICT architecture supporting strategy formulation on the basis of the viable system model. By applying the viable system model to the strategy-formulation process, it becomes possible to identify the functions required for strategy formulation, the relations between these functions, and the knowledge required by them.

By identifying the knowledge processes producing and processing this knowledge, and by linking these processes to the functions and the knowledge they require to contribute to the strategy-formulation process, it becomes possible to outline an ICT architecture supporting the processes of generating, retaining, sharing, and applying the knowledge needed for strategy formulation. This architecture consists of five modules dedicated to proposing, reviewing, finalizing, and consolidating strategy changes and related knowledge databases containing knowledge in the knowledge domains required for strategy formulation.

\section{REFERENCES}

Achterbergh, J. M. I. M., Beeres, R., \& Vriens, D. (2003). Does the balanced scorecard support organizational viability? Kybernetes, 32(9/10), 1387-1404.

Achterbergh, J. M. I. M., \& Vriens, D. (2002). Managing viable knowledge. Systems Research and Behavioral Science, 19, 223-241.

Beer, S. (1979). The heart of enterprise. Chichester, England: Wiley.

Beer, S. (1981). Brain of the firm. Chichester, England: Wiley.
Beer, S. (1985). Diagnosing the system. Chichester, England: Wiley.

Bukowitz, W. R., \& Williams, R. L. (1999). The knowledge management fieldbook. Edinburgh, Scotland: Pearson.

Davenport, T. H., \& Prusak, L. (1998). Working knowledge. Boston: Harvard Business School Press.

Espejo, R., Schumann, W., Schwaninger, M., \& Billello, U. (1996). Organizational transformation and learning. New York: Wiley.

Kaplan, R., \& Norton, D. (2001). The strategy-focused organization: How balanced scorecard companies thrive in the new business environment. Boston: Harvard Business School Press.

Laudon, K. C., \& Laudon, J. P. (1997). Management information systems (2nd ed.). Upper Saddle River, NJ: Prentice Hall.

Tan, D. S. (2003). Van informatiemanagement naar informatie-infrastructuurmanagement. Leiderdorp: Lansa.

Turban, E., McLean, E., \& Wetherbe, J. C. (2002). Information technology for management (3rd ed.). New York: Wiley.

\section{KEY TERMS}

ICT: Information and communication technology. ICT can be used to indicate the organization's technological infrastructure (comprising of all hardware, software, and telecommunications technology) and to indicate one or more specific collections of hardware, software, and telecommunications technology (i.e., one or more ICT applications).

ICT Architecture: The ICT architecture provides a conceptual model, specifying (at a general level) the parts of an ICT infrastructure (applications, databases, technological ICT elements) and their relations. In this chapter we concentrate on the application and databases parts.

Knowledge Domain: the knowledge related to defining, recognizing, and solving a specific problem.

Knowledge Processes: In the literature, one often finds four knowledge processes: (a) generating knowledge, (b) sharing knowledge, (c) storing knowledge, and (d) applying knowledge.

Strategy: In the literature, many definitions are given. A possible definition is the desired portfolio of productmarket-technology combinations of an organization. 
Strategy Formulation: The process by means of which the desired portfolio of product-market-technology combinations is defined and updated. This process can be modeled using the viable system model consisting of four steps: defining proposals for innovation, reviewing these proposals, finalizing proposals, and consolidating finalized proposals.
Viable System Model: This model is developed by Beer $(1979,1981)$ and specifies the necessary and sufficient functions organizations should possess to maintain a separate existence in their environment.

Viability: Viability is the ability of a system "to maintain a separate existence." Most organizations are continuously trying to maintain their viability. 